\title{
Complexation study and spectrofluorometric determination of the binding constant for diquat and $p$-sulfonatocalix[4]arene
}

\author{
Sinéad M. Mc Dermott*, Denise A. Rooney, Carmel B. Breslin \\ Department of Chemistry, National University of Ireland, Maynooth, Maynooth, Co. Kildare, Ireland
}

\section{A R T I C L E I N F O}

\section{Article history:}

Received 22 November 2011

Received in revised form 29 February 2012

Accepted 19 March 2012

Available online 28 March 2012

\section{Keywords:}

Diquat

p-Sulfonatocalix[4]arene

Ionic strength

Complexation constant

\begin{abstract}
A B S T R A C T
The interactions between diquat (DQ) and p-sulfonatocalix[4]arene (C4S) were studied in an aqueous solution as a function of the ionic strength. Evidence for the formation of a complex between DQ and C4S was obtained using fluorescence measurements, while the stoichiometry of the complex was confirmed as 1:1 for DQ/C4S using UV-vis spectroscopy. The ionic strength had no influence on the stoichiometry of the complex, but exerted a significant influence on the complexation constant, $K_{c}$, decreasing with an increase in the ionic strength. The thermodynamic complexation constant, $K_{\mathrm{c}}{ }^{\prime}$, was computed as $5.25 \pm 1.11 \times 10^{7}$ using the extended Debye-Hückel law. The rate constants for the heterogeneous electron transfer for the reduction of DQ at an electrode surface were evaluated as $0.150 \pm 0.010 \mathrm{~cm} \mathrm{~s}^{-1}$ in the absence of C4S and $0.065 \pm 0.010 \mathrm{~cm} \mathrm{~s}^{-1}$ when C4S was added to the solution in a 1:1 ratio.
\end{abstract}

(c) 2012 Elsevier Ltd. All rights reserved.

\section{Introduction}

Calix $[n]$ arenes are macrocyclic compounds synthesised from the condensation of phenol with formaldehyde. ${ }^{1} p$-Sulfonatocalix $\left.n\right]$ arenes (Fig. 1(a), p-sulfonatocalix[4]arene, C4S) are an important class of calix[ $n]$ arene, which are water soluble and have the ability to bind with a wide range of metal cations, organic ammonium cations and neutral organic molecules. ${ }^{2,3}$ This diverse supramolecular chemistry has led to their application in several fields including pharmaceutical chemistry, ${ }^{4}$ catalysis $^{5}$ and sensors. ${ }^{6}$ The ability of $p$-sulfonatocalix $n$ ] arenes to bind with viologens was first reported by Kaifer et al. ${ }^{7}$ More recently, it has been shown that the strong electrostatic interaction of the cationic viologen with the anionic calix $[n]$ arene can be enhanced by the $\pi-\pi$ interactions (a)

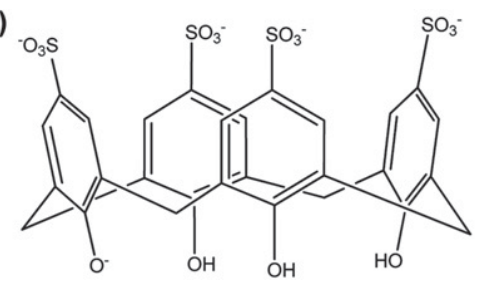

(b)

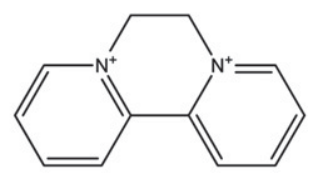

Fig. 1. (a) $p$-Sulfonatocalix [4]arene (C4S), which exists in the pentaionic form at $\mathrm{pH} 6.7$ and (b) diquat (DQ).

\footnotetext{
* Corresponding author. Tel.: +353 7083076; e-mail address: sinead.mcdermott@ nuim.ie (S.M. Mc Dermott).
}

between the host cavity and the guest molecule. ${ }^{8}$ Viologens are an important class of redox active compounds and the formation of supramolecular architectures, based on the complexation of $p$ sulfonatocalix[ $n$ ]arenes with viologens, has been investigated in the literature. ${ }^{9-14}$ Moreover, viologens are commonly used as herbicides and are potentially fatal to human health. ${ }^{15}$ Interestingly, a number of recent studies ${ }^{16,17}$ have investigated the potential of employing the complexation of $p$-sulfonatocalix[4]arenes with viologens as a therapeutic agent for methylviologen poisoning. The likelihood of medicinal applications of $p$-sulfonatocalix[4]arenes has increased as preliminary studies would indicate that C4S has a low toxicity. ${ }^{18-20}$

Diquat (DQ), Fig. 1(b), is a generally used herbicide, which is also toxic to humans. ${ }^{21}$ Work by Wang et al. ${ }^{17}$ have shown that DQ forms an inclusion complex with C4S. The complexation constants, determined using isothermal calorimetry, were $5.40 \times 10^{5} \mathrm{M}^{-1}$ and $7.95 \times 10^{5} \mathrm{M}^{-1}$ at $\mathrm{pH} 2.0$ and 7.2 , respectively. ${ }^{17}$ In addition, from the magnitude of the shift changes in the ${ }^{1} \mathrm{H}$ NMR signals of DQ upon complexation, it was reported that DQ binds with C4S in a sloping orientation. However, no study on the role and influence of ionic strength on the complexation was carried out. It is well recognised that host-guest complexation based on electrostatic interactions will decrease by increasing the ionic strength of the surrounding solution. ${ }^{22}$

In this paper the influence of ionic strength on the interaction of C4S with diquat (1,1'-ethylene-2,2'-bipyridinium) is assessed. The thermodynamic constant $\left(K_{\mathrm{c}}{ }^{\prime}\right)$ for the complexation of diquat by $p$ sulfonatocalix[4]arene was determined using the extended Debye-Hückel equation. In addition, the reduction of diquat to its 
radical cation was investigated in the presence and absence of the C4S. This study is important as it is known that the formation of the radical cation is an important intermediate in the biochemical mechanism of viologen toxicity. ${ }^{23}$

\section{Results and discussion}

\subsection{Stoichiometry of the DQ. C4S complex in solutions of low and high ionic strength}

The work by Wang et al. ${ }^{17}$ showed that the stoichiometry of the DQ. C4S complex was $1: 1$ at an ionic strength of $0.17 \mathrm{M}$ at a $\mathrm{pH}$ of 7.2. In the present study, the stoichiometry between DQ and C4S (Fig. 1) was evaluated using the continuous variation method ${ }^{24}$ at two ionic strengths of $I=4.24 \times 10^{-3}$ and $I=0.30 \mathrm{M}$. The ionic strength was maintained constant by the addition of $\mathrm{Na}_{2} \mathrm{SO}_{4}$. Fig. 2(a) and (b)

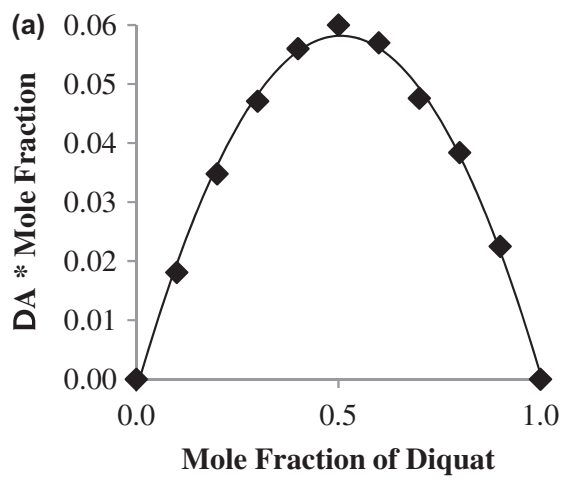

\section{2. ${ }^{1} \mathrm{H}$ NMR investigation of the interaction of DQ with C4S}

${ }^{1} \mathrm{H}$ NMR spectra were recorded at a fixed concentration of DQ $\left(4.86 \times 10^{-3} \mathrm{M}\right)$ in a $\mathrm{KCl}$ solution $(I=0.1 \mathrm{M})$ of $\mathrm{D}_{2} \mathrm{O}$ as a function of adding C4S up to a mole ratio of DQ/C4S of $1: 5$ and these data are presented in Fig. 3. As previously reported by Wang et al., ${ }^{17}$ upon addition of the C4S there was a strikingly large upfield shift in the signals for the protons on the heterocyclic rings. For example, the signal for $\mathrm{H}_{\mathrm{c}}$ shifted from 8.87 to $6.88 \mathrm{ppm}$. On the basis of the observed changes in chemical shifts, Wang et al. ${ }^{17}$ proposed that the geometry of the DQ.C4S complex is as shown in Fig. 4. The partial inclusion is consistent with the observation that the free and bound DQ undergoes fast exchange on the NMR timescale as only one resonance signal was observed for each of the equivalent protons in all the spectra recorded. It is likely that these large shifts were predominantly due to the close proximity of the protons on

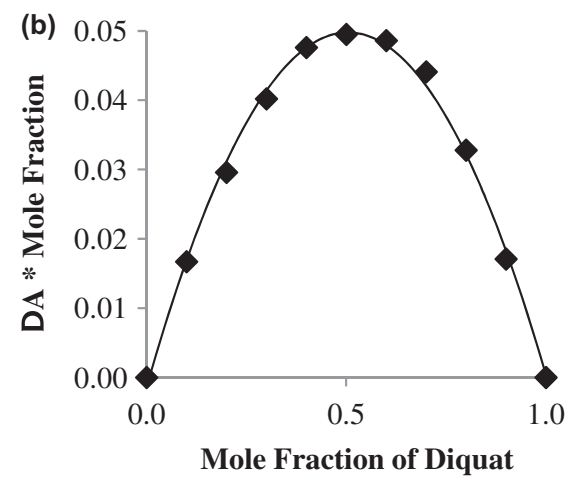

Fig. 2. Job's Plot of $\mathrm{DQ}$ and $\mathrm{C} 4 \mathrm{~S}$ carried out using UV-vis spectroscopy at an ionic strength of (a) $4.24 \times 10^{-3} \mathrm{M}$ and (b) $0.30 \mathrm{M}$, which was maintained constant using $\mathrm{Na}_{2} \mathrm{SO}_{4}$. The $\mathrm{pH}$ for these solutions was 6.7 .

shows the bell-shaped curves constructed from the data obtained using UV-vis spectroscopy. It is evident from both Fig. 2(a) and (b) that the maximum of each curve is centred at 0.5 , indicating the formation of a 1:1 complex in both solutions, with the ionic strength having little or no influence on the stoichiometry of the complex. the DQ molecule with the anionic sulfonate groups on the C4S. In addition, the interaction of the guest protons with the ring current of the aromatic nuclei of the host may also have contributed to the shift changes. A further striking observation from the spectra shown in Fig. 3 was the significant broadening of the proton signals

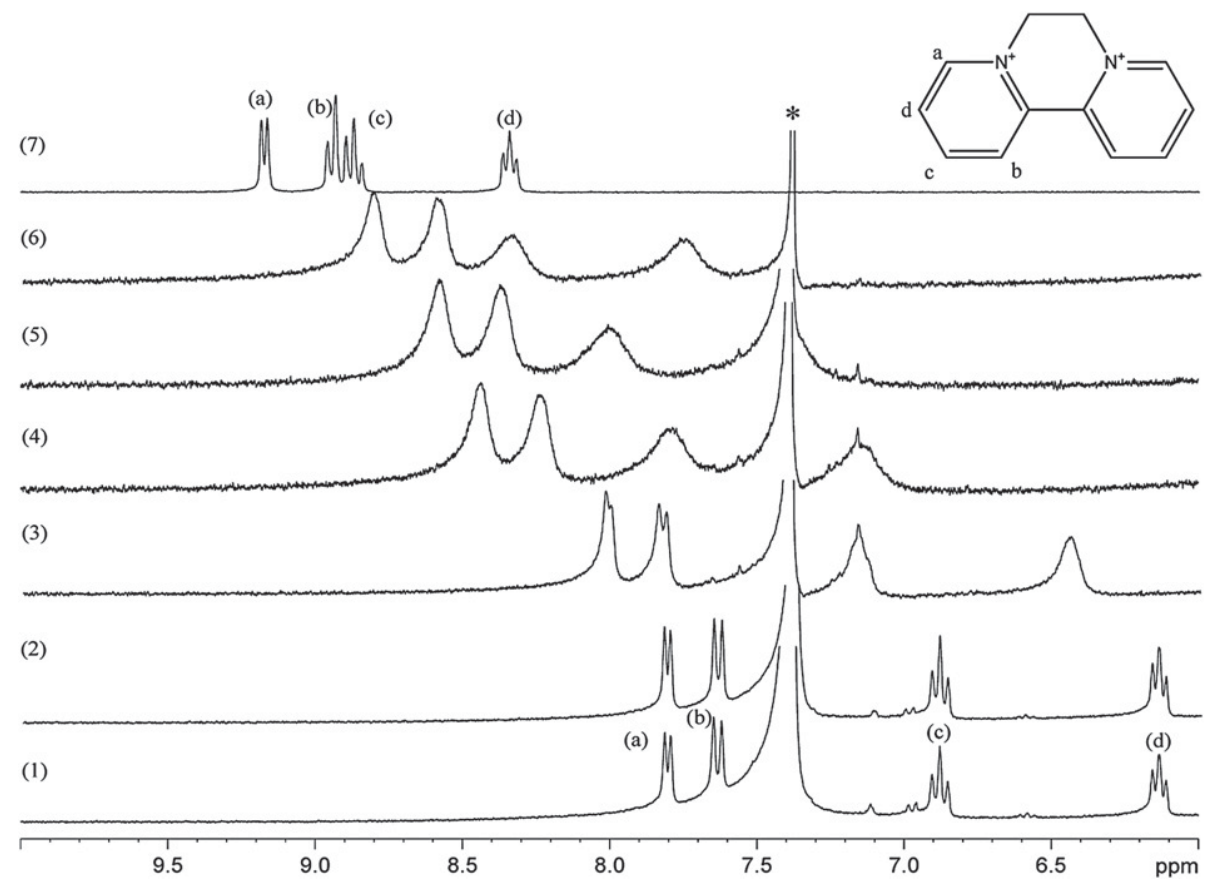

Fig. 3. ${ }^{1} \mathrm{H}$ NMR spectra of $4.86 \times 10^{-3} \mathrm{M}$ DQ with the following equivalents of C4S; (1) 5.00 , (2) 3.10 , (3) 1.00 , (4) 0.63 , (5) 0.50 , (6) 0.31 and (7) 0.00 . All solutions were prepared in $\mathrm{D}_{2} \mathrm{O}$ and the ionic strength of all solutions was maintained constant at $0.10 \mathrm{M}$ using $\mathrm{KCl}$. The pD of these solutions was 6.5 . The titration was carried out at $25{ }^{\circ} \mathrm{C}$. ${ }^{*}$ The peak at $7.40 \mathrm{ppm}$ arises from the aromatic hydrogen atoms on the $p$-sulfanocalix[4]arene. 


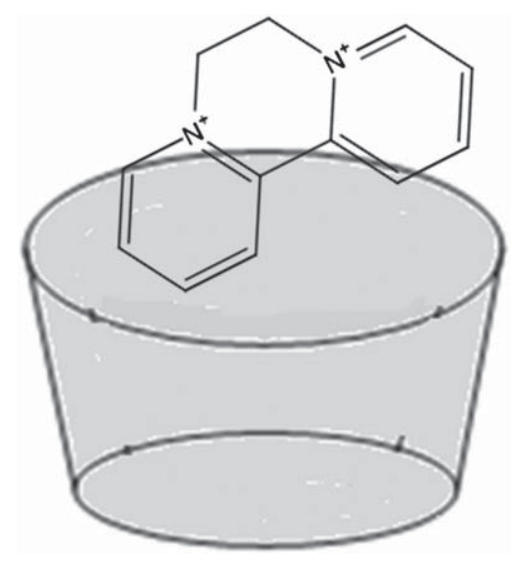

Fig. 4. Sloping orientation of the DQ. C4S complex as depicted by Guo et al. ${ }^{17}$

of DQ upon the addition of C4S below a mole ratio of $1: 1$. This broadening at such a low mole ratio is consistent with very strong binding between the guest and host. A similar broadening of the proton resonances has been observed on addition of cucurbit[7]uril to methylviologen in a $1: 1$ ratio and a binding constant of $1.03 \times 10^{5} \mathrm{M}^{-1}$ was determined for this complex. ${ }^{25}$ Moreover, at a mole ratio of $1: 1 \mathrm{DQ} / \mathrm{C} 4 \mathrm{~S}$ and above the signals for the protons on the DQ sharpened indicating that as the binding constant for DQ.C4S is so high at these concentrations of C4S, on the NMR timescale, there was essentially no free DQ in solution.

The addition of C4S to DQ not only affected the ${ }^{1} \mathrm{H}$ signals for DQ but it also altered the signals recorded for the protons on the methylene bridges of the $\mathrm{C} 4 \mathrm{~S}$. The ${ }^{1} \mathrm{H}$ NMR spectrum of $\mathrm{C} 4 \mathrm{~S}$ in a solution of $\mathrm{KCl}(\mathrm{I}=0.10 \mathrm{M})$ in $\mathrm{D}_{2} \mathrm{O}$ is shown in Fig. $5 \mathrm{a}$ and depicts the singlet signal, which is assigned to the hydrogen atoms on the methylene bridges. The hydrogen atoms of the methylene bridges were all equivalent on the NMR timescale as the calixarene is undergoing a fast conformational exchange between a number of conformers. ${ }^{26}$ However, a spectrum recorded for the $\mathrm{DQ} / \mathrm{C} 4 \mathrm{~S}$ mixture in a mole ratio of $1: 1$ (Fig. 5b) clearly shows that the signal for the methylene protons has split into two. This indicates that when the DQ is complexed by the $\mathrm{C} 4 \mathrm{~S}$, the C4S is held in the cone conformation in which the two hydrogen atoms on the methylene bridges are inequivalent. ${ }^{26}$

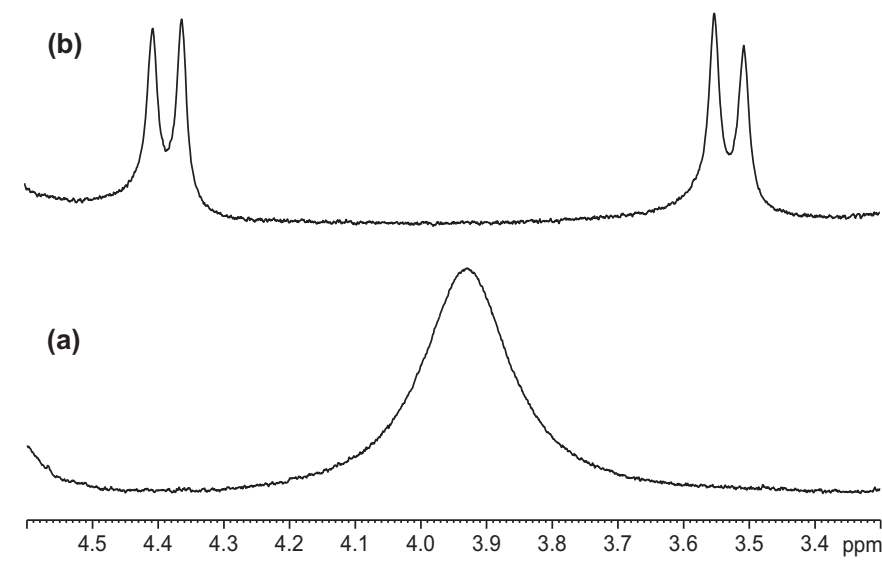

Fig. 5. ${ }^{1} \mathrm{H}$ NMR spectra of the methylene bridging protons of $\mathrm{C} 4 \mathrm{~S}$ in the presence of (a) 0.00 and (b) 1.00 equiv of $\mathrm{DQ}$. The $\mathrm{pD}$ of these solutions was 6.5 . The spectra were recorded at $25^{\circ} \mathrm{C}$.

\subsection{Evaluation of $K_{c}$ using fluorescence spectroscopy}

As previously reported, ${ }^{17} \mathrm{DQ}$ forms a complex with $\mathrm{C} 4 \mathrm{~S}$ in which the complexation constant, $K_{\mathrm{c}}$, was determined using isothermal calorimetry. As DQ is known to be weakly fluorescent at an excitation wavelength of $310 \mathrm{~nm}$ with an emission band between 320 and $500 \mathrm{~nm},{ }^{27}$ it is possible to determine $K_{\mathrm{c}}$ by monitoring the change of the DQ fluorescence intensity as a function of added C4S. Typical fluorescence spectra of DQ in the absence and presence of varying concentrations of C4S, to give an excess of C4S, are shown in Fig. 6. The solutions were held at a fixed ionic strength, $I=0.15 \mathrm{M}$, using $\mathrm{Na}_{2} \mathrm{SO}_{4}$. As can be seen in Fig. 2, there was a sharp decrease in the fluorescence intensity of DQ upon the addition of increasing concentrations of C4S. Upon addition of a 3-fold excess of C4S with respect to a fixed concentration of $D Q$, the fluorescence intensity of $D Q$ was essentially quenched, implying the formation of a strong complex. This is a somewhat unusual result, as generally, a fluorescence enhancement is recorded upon the addition of cationic aromatic molecules to uncharged macrocyclic hosts. ${ }^{27}$ The inclusion results in the guest experiencing a less polar environment, which reduces the number of nonradiative pathways available to deactivate the excited state. However, host-guest complexation by $p$-sulfonatocalix[ $n]$ arenes have been previously reported to have a quenching effect on the guest fluorescence. ${ }^{28-30}$ It has been proposed that this effect arises as the cavity of the $p$-sulfonatocalix[ $n$ ] arene is hydrophilic in character and the electrostatic interaction between the guest and the sulfonate groups has a strong quenching effect. ${ }^{30}$

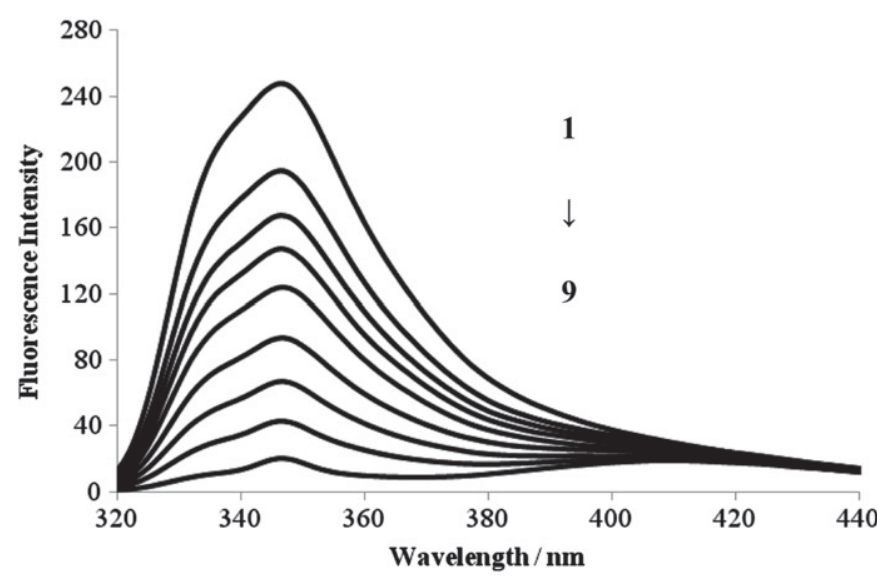

Fig. 6. Fluorescence spectra of $1.00 \times 10^{-5} \mathrm{M}$ DQ in the presence of (1) 0.00 , (2) $2.19 \times 10^{-6}$, (3) $3.64 \times 10^{-6}$, (4) $6.07 \times 10^{-6}$, (5) $8.00 \times 10^{-6}$, (6) $1.01 \times 10^{-5}$, (7) $1.30 \times 10^{-5}$, (8) $1.69 \times 10^{-5}$ and (9) $2.81 \times 10^{-5} \mathrm{M} \mathrm{C4S}$ at a constant ionic strength, $I=0.15 \mathrm{M}$ using $\mathrm{Na}_{2} \mathrm{SO}_{4}$, at $25^{\circ} \mathrm{C}$. The $\mathrm{pH}$ of these solutions was 6.7 .

The equilibrium between the complex (DQ. C4S), guest (DQ) and host (C4S) molecules is shown in Eq. 1. To quantify the strength of the interaction between DQ and C4S, $K_{\mathrm{c}}$ is calculated in accordance with Eq. 2, where [DQ], [C4S] and [DQ.C4S] are the equilibrium concentrations.

$\mathrm{C} 4 \mathrm{~S}+\mathrm{DQ} \rightleftharpoons \mathrm{DQ} \cdot \mathrm{C} 4 \mathrm{~S}$

$K_{\mathrm{c}}=\frac{[\mathrm{DQ} \cdot \mathrm{C} 4 \mathrm{~S}]}{[\mathrm{C} 4 \mathrm{~S}] \cdot[\mathrm{DQ}]}$

As DQ was the fluorescent guest probe being monitored, the fluorescence intensity of DQ is the product of the molar fluorescence intensity $\left(\varepsilon_{\mathrm{F}}\right)$ and the concentration of the DQ molecule as shown in Eq. 3. The fluorescence of DQ in the absence and presence of the host, C4S, is calculated in accordance with Eqs. 4 and 5, where $[\mathrm{DQ}]_{0}$ is the initial concentration of the guest molecule and $\varepsilon_{\mathrm{F}}$ and $\varepsilon_{\mathrm{F}}^{\prime}$ represents the molar fluorescence intensity of the free and complexed $\mathrm{DQ}$ respectively. The change of fluorescence intensity, $\Delta F$, is evaluated using Eq. 6 , where $\Delta \varepsilon_{\mathrm{F}}$ is the change in the molar fluorescence intensity. 
$F=\varepsilon_{F} C_{D Q}$

$F_{0}=\varepsilon_{\mathrm{F}}[\mathrm{DQ}]_{0}$

$F=\varepsilon_{\mathrm{F}}[\mathrm{DQ}]+[\mathrm{DQ} \cdot \mathrm{C} 4 \mathrm{~S}]=\varepsilon_{\mathrm{F}}[\mathrm{DQ}]_{0}+\left(\varepsilon_{\mathrm{F}}^{\prime}-\varepsilon_{\mathrm{F}}\right)[\mathrm{DQ} \cdot \mathrm{C} 4 \mathrm{~S}]$

$\Delta F=F-F_{0}=\left(\varepsilon_{\mathrm{F}}^{\prime}-\varepsilon_{\mathrm{F}}\right)[\mathrm{DQ} \cdot \mathrm{C} 4 \mathrm{~S}]=\Delta \varepsilon_{\mathrm{F}}[\mathrm{DQ} \cdot \mathrm{C} 4 \mathrm{~S}]$

The concentrations of the DQ and C4S are given by the difference between the initial $\mathrm{DQ},[\mathrm{DQ}]_{0}$, and $\mathrm{C} 4 \mathrm{~S},[\mathrm{C} 4 \mathrm{~S}]_{0}$, concentrations and the concentration of the DQ.C4S complex, as shown in Eqs. 7 and 8.

$[\mathrm{C} 4 \mathrm{~S}]=[\mathrm{C} 4 \mathrm{~S}]_{0}-[\mathrm{DQ} \cdot \mathrm{C} 4 \mathrm{~S}]$

$[\mathrm{DQ}]=[\mathrm{DQ}]_{0}-[\mathrm{DQ} \cdot \mathrm{C} 4 \mathrm{~S}]$

Considering the change in fluorescence intensity as a function of the DQ and C4S initial concentrations, Eqs. 2, 6-8 can be combined to give Eq. 9 and $\Delta F$ is calculated in accordance with Eq. $10 .^{30,31}$

$\Delta F^{2}-\Delta \varepsilon_{\mathrm{F}}\left([\mathrm{C} 4 \mathrm{~S}]_{0}+[\mathrm{DQ}]_{0}+\frac{1}{K_{\mathrm{C}}}\right) \Delta F+\Delta \varepsilon_{\mathrm{F}}^{2}[\mathrm{C} 4 \mathrm{~S}]_{0}[\mathrm{DQ}]_{0}=0$

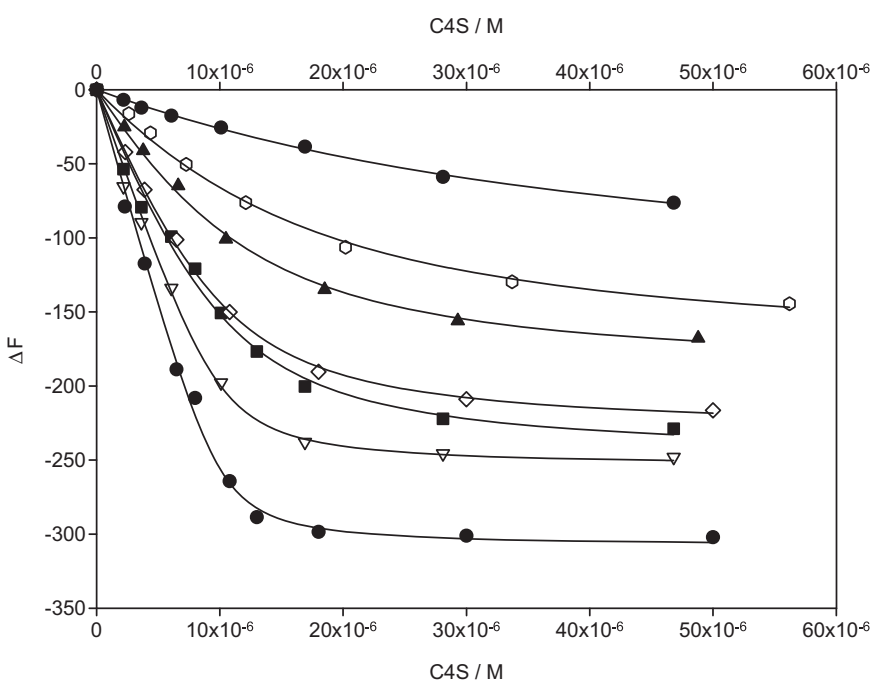

Fig. 7. Plot of the change in fluorescence intensity of DQ as a function of added $C 4 S$ at the following ionic strengths; $(\bullet) 1.50,(O) 0.60,(\Delta) 0.30,(\diamond) 0.21,(\boldsymbol{\square}) 0.15,(\nabla)$ 0.09 and $(\bullet) 0.03 \mathrm{M}$. Solutions held at $25^{\circ} \mathrm{C}$. The ionic strength upon addition of C4S was maintained constant using the required amount of $\mathrm{Na}_{2} \mathrm{SO}_{4}$. The $\mathrm{pH}$ of these solutions was 6.7.

$\Delta F=\frac{\Delta \varepsilon_{\mathrm{F}}\left([\mathrm{C} 4 \mathrm{~S}]_{0}+[\mathrm{DQ}]_{0}+\frac{1}{K_{\mathrm{c}}}\right) \pm \sqrt{\Delta \varepsilon_{\mathrm{F}}^{2}\left([\mathrm{C} 4 \mathrm{~S}]_{0}+[\mathrm{DQ}]_{0}+\frac{1}{K_{\mathrm{c}}}\right)^{2}-4 \Delta \varepsilon_{\mathrm{F}}^{2}[\mathrm{C} 4 \mathrm{~S}]_{0}[\mathrm{DQ}]_{0}}}{2}$

The influence of ionic strength on the magnitude of $K_{\mathrm{c}}$ has been documented by Ong and Kaifer ${ }^{32}$ in which it was reported that the choice of salt in maintaining a constant ionic strength also impacts on $K_{\mathrm{c}}$. Although, $p$-sulfonatocalix[ $\left.n\right]$ arenes have a high affinity for inorganic cations, in particular divalent and trivalent cations, monovalent cations show much weaker binding abilities. ${ }^{8}$ Hence, the salt, $\mathrm{Na}_{2} \mathrm{SO}_{4}$, was chosen to control the ionic strength of solutions.

Plots of the change in fluorescence intensity $(\Delta F)$ as a function of the host, C4S, concentration were constructed and curves fitted in accordance with Eq. 10 to determine the $K_{\mathrm{c}}$ values. Representative plots are shown in Fig. 7, while the computed $K_{\mathrm{c}}$ is shown as a function of the ionic strength in Table 1 . The good curve fitting as shown by the plots in Fig. 7 and the $R^{2}$ values given in Table 1 support the 1:1 stoichiometry of the DQ.C4S complex in all the solutions investigated. There was a considerable decrease in the magnitude of $K_{\mathrm{c}}$ with increasing ionic strength (Table 1). Approximately a 100 -fold decrease in the value of $I_{\text {ce }}$ was observed upon increasing the ionic strength of the solution from $0.03 \mathrm{M}$ to $1.50 \mathrm{M}$. Previous studies by Wenz et al..$^{33}$ on a cationic cyclodextrin with an anionic guest have shown that the electrostatic input of the binding free energy was affected by an increase in the ionic strength. Our findings, that $K_{\mathrm{c}}$ decreased significantly with increasing ionic strength and that the fluorescence intensity of DQ was quenched upon forming a host-guest complex with the C4S are consistent with electrostatic interactions having a significant contribution to the binding of $p$-sulfonatocalix[4]arenes with cationic guests.

\subsection{Determination of the thermodynamic complexation constant for the DQ. C4S complex}

It is clearly evident from the data presented in Table 1 that the magnitude of $K_{\mathrm{c}}$ is influenced by the ionic strength. Given that DQ and C4S are highly charged, it is more accurate to express $K_{c}$ in terms of the activity coefficients of the charged species and accordingly the thermodynamic complexation constant, $K_{\mathrm{c}}{ }^{\prime}$ as shown in Eq. 11 , where $\gamma$ represents the activities of the charged host and guest species. This equation can be expressed in a logarithmic form to give Eq. $12 .{ }^{22}$

$K_{\mathrm{c}}^{\prime}=K_{\mathrm{c}} \cdot \frac{\gamma_{\mathrm{DQ}} \cdot \mathrm{C} 4 \mathrm{~S}}{\gamma_{\mathrm{DQ}} \gamma_{\mathrm{C} 4 \mathrm{~S}}}$

Table 1

$K_{\mathrm{c}}$ values for the DQ.C4S complex at varying ionic strength concentrations at a temperature $25^{\circ} \mathrm{C}$. The varying quantities of C4S were added to a fixed concentration of $1.0 \times 10^{-5} \mathrm{M}$ DQ

\begin{tabular}{lll}
\hline Ionic strength/M & $K_{\mathrm{c}}^{\mathrm{a}} / \mathrm{M}^{-1}$ & $R^{2}$ \\
\hline 0.03 & $2.84 \times 10^{6}$ & 0.996 \\
0.09 & $1.67 \times 10^{6}$ & 0.996 \\
0.15 & $5.00 \times 10^{5}$ & 0.991 \\
0.21 & $4.34 \times 10^{5}$ & 0.999 \\
0.30 & $1.94 \times 10^{5}$ & 0.997 \\
0.60 & $9.13 \times 10^{4}$ & 0.996 \\
1.50 & $2.72 \times 10^{4}$ & 0.998 \\
\hline
\end{tabular}

a Values were the averages of three separate measurements, errors are $<5 \%$ of the values reported, $\Delta \varepsilon_{\mathrm{F}}$ was of the order of $1.0 \times 10^{7}$ A.U. $\mathrm{M}^{-1}$ for each solution studied. 
$\log K_{\mathrm{c}}^{\prime}=\log K_{\mathrm{c}}+\log \left[\frac{\gamma_{\mathrm{DQ} \cdot \mathrm{C} 4 \mathrm{~S}}}{\gamma_{\mathrm{DQ}} \gamma_{\mathrm{C} 4 \mathrm{~S}}}\right]$

The activity coefficients may be obtained from the extended Debye-Hückel law (Eq. 13), in which $\Delta z^{2}$ corresponds to the effective charge of the ions, $I$ is the ionic strength, $A$ is constant with a value of 0.51 at a temperature of $25^{\circ} \mathrm{C}$ and $\mathrm{Ba}$ is assumed to be 2 for large organic ions. ${ }^{34}$ Using Eqs. 12 and $13, K_{\mathrm{c}}{ }^{\prime}$ can be expressed in terms of $K_{\mathrm{c}}$ and the ionic strength of the solution to give Eq. $14 .^{34,35}$

$\log \gamma \pm=\frac{-A \Delta z^{2} \sqrt{I}}{1+\mathrm{Ba} \sqrt{I}}$

$\log K_{\mathrm{c}}=\log K_{\mathrm{c}}^{\prime}-\frac{A \Delta z^{2} \sqrt{I}}{1+\operatorname{Ba} \sqrt{I}}$

The $K_{\mathrm{c}}$ values obtained from the fluorescence experiments combined with the corresponding ionic strength values (Table 1) were plotted in accordance with Eq. 14 generating a linear plot as shown in Fig. 8. The slope of the plot was determined to be 9.0, which corresponded well with the value of 10.2 calculated from Eq. 14 using the effective charge of the system. Surprisingly, given the large non-symmetrical size and uneven charge distribution of the DQ.C4S system, the data fit well to the extended Debye-Hückel law. However, previous studies have shown that the effect of ionic strength on the binding of cation organic guests to anionic macrocycles can be correlated using the Debye-Hückel theory. ${ }^{22,34-36}$ The extrapolation of the plot in Fig. 8 gave a value for the thermodynamic complexation constant, $K_{\mathrm{c}}{ }^{\prime}$, of $5.25 \pm 1.11 \times 10^{7}$. This high value highlights the significant degree of complexation of DQ by C4S. This high value highlights the significant degree of complexation of DQ by C4S. In comparison, the binding constants of DQ with cucurbil[7]uril and cucurbil[8]uril in a $0.1 \mathrm{M}$ phosphate buffer $(\mathrm{pH}=7)$ solution have previously been determined to have values of 350 and $4.8 \times 10^{4} \mathrm{M}^{-1}$, respectively. ${ }^{27}$

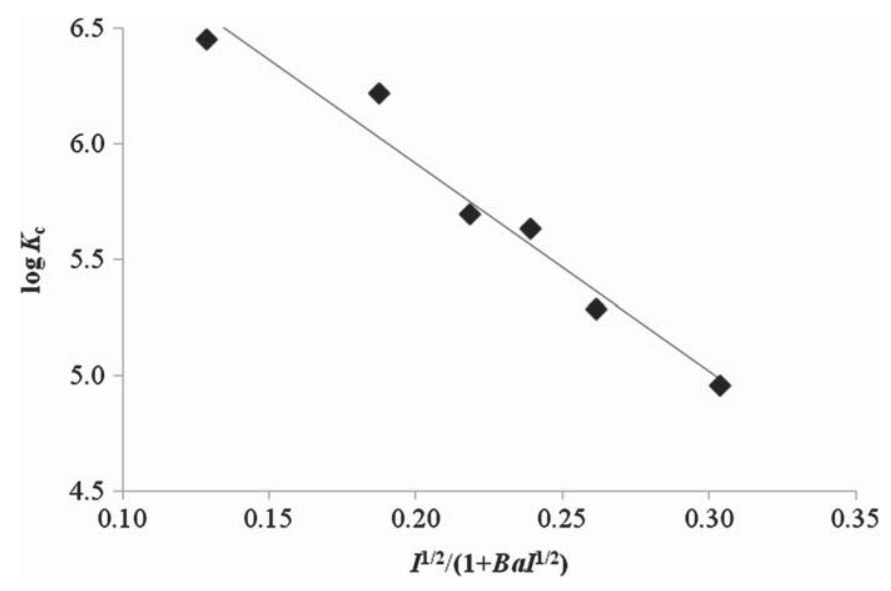

Fig. 8. Debye-Hückel plot of $\log K_{\mathrm{c}}$ as a function of ionic strength $\left(I^{1 / 2} / 1+\mathrm{Ba} I^{1 / 2}\right)$.

\subsection{The effect of complexation by C4S on the rate constant for the reduction of $\mathrm{DQ}^{2+}$}

As documented in the literature, ${ }^{17}$ the formation of viologen C C4S complexes have shown promise as potential treatments of viologen poisoning. The toxicity of diquat arises because in the body it is enzymatically converted to the radical cation which catalyses the reduction of $\mathrm{O}_{2}$ to $\mathrm{O}_{2} \cdot{ }^{-}$. When diquat is ingested in high doses over a short period of time $\mathrm{O}_{2} \cdot{ }^{-}$is formed in a high concentration. Under these conditions it is not removed sufficiently quickly from the body and is thus able to generate substantial amounts of other reactive species of oxygen and subsequently harmful toxic radicals such as $\mathrm{HO} \cdot$. Cyclic voltammetry studies have shown that upon complexation by C4S the first reduction potential of DQ was significantly shifted to more negative potentials. ${ }^{17}$ Therefore, it was postulated that one of the roles played by the DQ. C4S complex in lowering DQ toxicity is that, generation of the diquat radical is made more difficult and so, less of this species is produced in the body. It is likely that complexation of the DQ by C4S will also cause the reduction of DQ to become kinetically disfavoured. In light of this, the rate constants for the reduction of DQ to the DQ radical species in the absence and presence of C4S (DQ/ C4S in 1:1 mole ratio) were evaluated electrochemically using the Koutecký-Levich equation (Eq. 15). ${ }^{37}$

$\frac{1}{i_{\mathrm{L}}}=\frac{1}{n F A k_{\mathrm{DQ}} c}+\frac{1.61}{n F A^{-1 / 6} D^{2 / 3} \omega^{1 / 2} c}$

In this equation, $i_{\mathrm{L}}$ is the limiting current, $F$ is Faraday's constant, $n$ is the number of electrons transferred, $A$ is the surface area of the electrode, $k_{\mathrm{DQ}}$ is the rate constant for the electrochemical reduction of $\mathrm{DQ}^{2+}$ to $\mathrm{DQ}^{+}, c$ is the concentration of $\mathrm{DQ} v$ is the kinematic viscosity, $D$ is the diffusion coefficient and $\omega$ is the angular velocity. Voltammograms were recorded at different rotations rates and the limiting current was measured as a function of the rotation rate. Plots of the inverse of the limiting current as a function of the inverse of the rotation rate are shown in Fig. 9. The heterogeneous electron transfer rate constant, $k_{\mathrm{DQ}}$, was obtained from the intercept to give values of $0.150 \pm 0.010 \mathrm{~cm} \mathrm{~s}^{-1}$ for free DQ and $0.065 \pm 0.010 \mathrm{~cm} \mathrm{~s}^{-1}$ for DQ in the presence of C4S, DQ.C4S complex. The large value of $k_{\mathrm{DQ}}$ for free $\mathrm{DQ}$ is consistent with literature values on related systems, and it is well established that many bipyridinium dication/radical cation couples show fast heterogeneous electron transfer. ${ }^{27,38,39}$ The significant reduction in $k_{\mathrm{DQ}}$ on addition of C4S is consistent with the DQ bound in an inclusion complex. A number of studies on the electrochemistry of encapsulated redox active guests indicate that the direct electron transfer from the inclusion complex does not occur. ${ }^{40-43}$ The guest must first dissociate from the host before the electron transfer step occurs and it is this step, which slows down the observed rate constant for the electron transfer step. It is likely that a similar dissociation step followed by the electron transfer step occurred for the DQ.C4S system studied here.

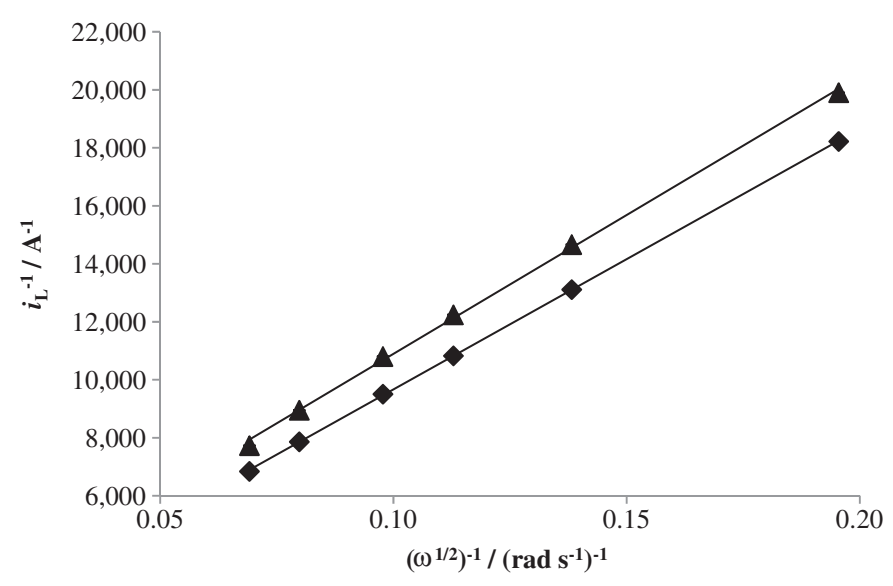

Fig. 9. Koutechy-Levich plots of $i_{\mathrm{L}}^{-1}$ as a function of $\left(\omega^{1 / 2}\right)^{-1}$. These data (the average of three independent measurements, errors are $<2 \%$ ) were plotted from RDVs carried out using $8.0 \times 10^{-4} \mathrm{M}$ DQ in the presence of $(\bullet) 0.0$ and $(\boldsymbol{\Delta}) 4.0 \times 10^{-3} \mathrm{M}$ C4S in a solution of $\mathrm{Na}_{2} \mathrm{SO}_{4}$ of $I=1.50 \mathrm{M}$. The $\mathrm{pH}$ of these solutions was 6.7 . 


\section{Conclusions}

DQ formed a 1:1 complex with C4S in solutions of high and low ionic strength, with the ionic strength having no observable influence on the stoichiometry of the complex. Large shifts in the ${ }^{1} \mathrm{H}$ NMR signals of DQ and changes in the line widths were observed on addition of $\mathrm{C} 4 \mathrm{~S}$, indicating the formation of a strong inclusion complex. The ${ }^{1} \mathrm{H}$ NMR spectroscopy data also showed that for the DQ. C4S complex the C4S was held in the cone conformation. Interestingly, the fluorescence intensity of DQ was quenched upon complexation by $\mathrm{C} 4 \mathrm{~S}$, indicating that the C4S cavity has little hydrophobic character. The DQ.C4S complexation constant, $K_{\mathrm{c}}$, decreased significantly with an increase in the ionic strength of the solution. The thermodynamic constant, $K_{\mathrm{c}}{ }^{\prime}$, was computed as $5.25 \pm 1.11 \times 10^{7}$ using the extended Debye-Hückel Law, indicating that the DQ.C4S complex is held together predominantly by electrostatic forces of attraction. Encapsulation of DQ by C4S kinetically hinders the electron transfer reaction to form the $\mathrm{DQ}^{+} \cdot$ radical. It is likely that this effect, which will led to reducing the amount of this toxic species formed in the body, contributes to C4S known ability to be able to act as an antidote towards viologen poisoning.

\section{Experimental}

\subsection{Materials}

Sodium sulfate, $\mathrm{Na}_{2} \mathrm{SO}_{4}$, potassium chloride, $\mathrm{KCl}$, deuterium oxide, $\mathrm{D}_{2} \mathrm{O}$, and diquat dibromide monohydrate $\mathrm{C}_{12} \mathrm{H}_{12} \mathrm{Br}_{2} \mathrm{~N}_{2} \cdot \mathrm{H}_{2} \mathrm{O}$ (PESTA $\mathrm{NAL}^{\circledR}$, analytical standard) were obtained from Sigma-Aldrich. p-tert-Butylcalix[4]arene, which was prepared according to the method outlined by Gutsche et al. ${ }^{44}$ and was converted to the $p$ sulfonatocalix[4]arene sodium salt using literature procedures. ${ }^{45}$ At the $\mathrm{pH}$ range of 6.7, in the present study, the $p$-sulfonatocalix[4]arene is penta-anionic as one pheonlic group on the lower rim is deprotonated. ${ }^{46,47}$ All aqueous solutions were prepared in distilled $\mathrm{H}_{2} \mathrm{O}$.

\subsection{Instrumentation}

The construction of the Job's plot was carried out using a Unicam UV-500 spectrometer. Fluorescence measurements were carried out using either a Cary Eclipse fluorescence spectrometer or a JascoFP6300 spectrometer. All electrochemical measurements were recorded using a Solartron potentiostat (Model SI 1285). A threecell electrode system was employed for the electrochemical experiments, which consisted of a saturated calomel reference electrode (SCE), an auxiliary platinum electrode and a working gold electrode, $3 \mathrm{~mm}$ in diameter. The gold electrode was polished using diamond paste (Buehler diamond suspensions, $1 \mu \mathrm{m}$ ) to give a smooth surface, rinsed with distilled water, sonicated to remove any residues from the polishing and dried. ${ }^{1} \mathrm{H}$ NMR spectra were recorded on a Bruker Avance $300 \mathrm{MHz}$ spectrometer.

\subsection{Procedures}

The stoichiometry of the complex formed between DQ and C4S was determined using the continuous variation or Job's method. UV-vis spectroscopy was used to evaluate the stoichiometry of the complex through the change in absorption of DQ at $310 \mathrm{~nm}$ as a function of the change in mole fraction of $D Q$. The ionic strength of all solutions was maintained constant through the addition of $\mathrm{Na}_{2} \mathrm{SO}_{4}$ and was calculated using Eq. 16 in which, $I$ is the ionic strength, $c_{i}$ and $z_{i}$ are the concentration and charge on the $i^{\text {th }}$ ion, respectively. Job's plots were constructed at two different ionic strengths, $4.24 \times 10^{-4}$ and $0.30 \mathrm{M}$ (using $\mathrm{Na}_{2} \mathrm{SO}_{4}$ ) and the stoichiometry evaluated through the maximum of the bell-shaped curve. The solutions were held in a thermostated water bath at $25^{\circ} \mathrm{C}$.
$I=\frac{1}{2} \sum_{i=0}^{n} c_{i} z_{i}^{2}$

${ }^{1} \mathrm{H}$ NMR spectra were recorded of DQ $(4.86 \mathrm{mM})$ dissolved in a $\mathrm{KCl}$ solution $(I=0.1 \mathrm{M})$ in $\mathrm{D}_{2} \mathrm{O}$ as a function of adding $C 4 \mathrm{~S}$ up to a $\mathrm{DQ} / \mathrm{C} 4 \mathrm{~S}$ mole ratio of 1:5.

The measure of interaction $\left(K_{\mathrm{c}}\right)$ between DQ and C4S was quantified by carrying out a host-guest titration using fluorescence spectroscopy, in which the guest concentration remained fixed at $1.0 \times 10^{-5} \mathrm{M}$ DQ and the host concentration was varied in the range of $0.0-5.0 \times 10^{-5} \mathrm{MC}$ CS. The excitation wavelength of DQ used in the titration was $310 \mathrm{~nm}$ and the emission band was monitored from 320 to $500 \mathrm{~nm}$. As the ionic strength of the solution was altered upon each addition of the C4S, titrations were carried out at fixed ionic strength values $(0.03,0.09,0.15,0.21,0.30,0.60$ and $1.50 \mathrm{M})$ by adding the required concentration of $\mathrm{Na}_{2} \mathrm{SO}_{4}$ to each solution. The solutions were held in a thermostated water bath at $25^{\circ} \mathrm{C}$.

Rotating disc voltammetry was used to determine the rate constant for the heterogeneous electron transfer for the reduction of $\mathrm{DQ}^{2+}$ to $\mathrm{DQ}^{+}$in the absence and presence of C4S. This technique ensures that the diffusion of the electrochemical species to the electrode surface is controlled by convection. ${ }^{48} \mathrm{DQ}$ is electrochemically active, ${ }^{49}$ with the reduction potential for $\mathrm{DQ}^{2+}$ to $\mathrm{DQ}^{+}$ occurring at approximately $-0.7 \mathrm{~V}$ versus SCE. Voltammograms were recorded for $8.0 \times 10^{-4} \mathrm{M}$ DQ in the absence and presence of $8.0 \times 10^{-4} \mathrm{M} \mathrm{C} 4 \mathrm{~S}$, and the potential was swept from -0.1 to $-1.0 \mathrm{~V}$ versus SCE at $50 \mathrm{mV} \mathrm{s}^{-1}$ at varying rotation rates at a gold working electrode. All solutions were prepared in $\mathrm{Na}_{2} \mathrm{SO}_{4}$ in which the ionic strength remained constant at $1.5 \mathrm{M}$.

\section{Acknowledgements}

We gratefully acknowledge Science Foundation Ireland Research Frontiers Programme (06/RFP/EEB006) for the financial assistance for this work.

\section{References and notes}

1. Böhmer, V. Angew. Chem., Int. Ed. Engl. 1995, 34, 713-745.

2. Coleman, A. W.; Bott, S. G.; Morley, S. D.; Means, C. M.; Robinson, K. D.; Zhang H.; Atwood, J. L. Angew. Chem. 1988, 100, 1412-1413.

3. Shinkai, S.; Mori, S.; Tsubaki, T.; Sone, T.; Manabe, O. Tetrahedron Lett. 1984, 25 5315-5318.

4. Danylyuk, O.: Suwinska, K. Chem. Commun. 2009, 5799-5813.

5. Karakhanov, E.; Buchneva, T.; Maximov, A.; Zavertyaeva, M. J. Mol. Catal. A: Chem. 2002, 184, 11-17.

6. Xiong, D.; Chen, M.; Li, H. Chem. Commun. 2008, 880-882.

7. Bernardo, A. R.; Lu, T. B.; Cordova, E.; Zhang, L. T.; Gokel, G. W.; Kaifer, A. E. J. Chem. Soc., Chem. Commun. 1994, 529-530.

8. Guo, D. S.; Wang, K.; Liu, Y. J. Inclusion Phenom. Macrocycl. Chem. 2008, 62, 1-21.

9. Erra, L.; Tedesco, C.; Vaughan, G.; Brunelli, M.; Troisi, F.; Gaeta, C.; Neri, P. CrystEngComm 2010, 12, 3463-3466.

10. Guo, D.-S.; Chen, S.; Qian, H.; Zhang, H.-Q.; Liu, Y. Chem. Commun. 2010, 2620-2622.

11. Guo, D.-S.; Su, X.; Liu, Y. Cryst. Growth Des. 2008, 8, 3514-3517.

12. Kaliappan, R.; Ling, Y.; Kaifer, A. E.; Ramamurthy, V. Langmuir 2009, 25 $8982-8992$

13. Wang, K.; Guo, D.-S.; Wang, X.; Liu, Y. ACS Nano 2011, 5, 2880-2894.

14. Gaeta, C.; Caruso, T.; Mincolelli, M.; Troisi, F.; Vasca, E.; Neri, P. Tetrahedron 2008, 64, 5370-5378.

15. Dinis-Oliveira, R. J.; Remião, F.; Duarte, J. A.; Ferreira, R.; Navarro, A. S.; Bastos, M. L.; Carvalho, F. Free Radic. Biol. Med. 2006, 41, 1213-1224.

16. Wang, G.-F.; Ren, X.-L.; Zhao, M.; Qiu, X.-L.; Qi, A.-D. J. Agric. Food Chem. 2011 59, 4294-4299.

17. Wang, K.; Guo, D. S.; Zhang, H. Q.; Li, D.; Zheng, X. L.; Liu, Y. J. Med. Chem. 2009 $52,6402-6412$.

18. Coleman, A. W.; Jebors, S.; Cecillon, S.; Perret, P.; Garin, D.; Marti-Battle, D. Moulin, M. New J. Chem. 2008, 32, 780-782.

19. Da Silva, E.; Shahgaldian, P.; Coleman, A. W. Int. J. Pharm. 2004, 273, 57-62.

20. Paclet, M.-H.; Rousseau, C. F.; Yannick, C.; Morel, F.; Coleman, A. W. J. Inclusion Phenom. Macrocycl. Chem. 2006, 55, 353-357.

21. Adams, J. R.; Nusrath, M.; Bryant, D. G. Br. J. Oral Maxillofac. Surg. 2008, 46 601-602. 
22. Schneider, H. J.; Kramer, R.; Simova, S.; Schneider, U. J. Am. Chem. Soc. 1988, 110, 6442-6448.

23. Dinis-Oliveira, R. J.; Duarte, J. A.; Sanchez-Navarro, A.; Remiao, F.; Bastos, M. L.; Carvalho, F. Crit. Rev. Toxicol. 2008, 38, 13-71.

24. Gil, V. M. S.; Oliveira, N. C. J. Chem. Educ. 1990, 67, 473.

25. Ong, W.; Gomez-Kaifer, M.; Kaifer, A. E. Org. Lett. 2002, 4, 1791-1794.

26. Shinkai, S.; Araki, K.; Kubota, M.; Arimura, T.; Matsuda, T. J. Org. Chem. 1991, 56, 295-300.

27. Ling, Y. H.; Mague, J. T.; Kaifer, A. E. Chem.-Eur. J. 2007, 13, 7908-7914.

28. Guo, D.-S.; Uzunova, V. D.; Su, X.; Liu, Y.; Nau, W. M. Chem. Sci. 2011, 2, 1722-1734.

29. Liu, Y.; Han, B. H.; Chen, Y. T. J. Org. Chem. 2000, 65, 6227-6230.

30. Liu, Y.; Han, B. H.; Chen, Y. T. J. Phys. Chem. B 2002, 106, 4678-4687.

31. Liu, Y.; Han, B. H.; Zhang, H. Y. Curr. Org. Chem. 2004, 8, 35-46.

32. Ong, W.; Kaifer, A. E. J. Org. Chem. 2004, 69, 1383-1385.

33. Wenz, G.; Strassnig, C.; Thiele, C.; Engelke, A.; Morgenstern, B.; Hegetschweiler, K. Chem.-Eur. J. 2008, 14, 7202-7211.

34. Kubinyi, M.; Vidoczy, T.; Varga, O.; Nagy, K.; Bitter, I. Appl. Spectrosc. 2005, 59, 134-139.

35. Varga, O.; Kubinyi, M.; Vidoczy, T.; Baranyai, P.; Bitter, I.; Kallay, M. J. Photochem. Photobiol., A 2009, 207, 167-172.
36. Zia, V.; Rajewski, R. A.; Stella, V. J. Pharm. Res. 2001, 18, 667-673.

37. Treimer, S.; Tang, A.; Johnson, D. C. Electroanalysis 2002, 14, 165-171.

38. Credi, A.; Dumas, S.; Silvi, S.; Venturi, M.; Arduini, A.; Pochini, A.; Secchi, A. J. Org. Chem. 2004, 69, 5881-5887.

39. Monk, P. M. S. The Viologens: Physicochemical Properties, Synthesis and Applications of the Salts of 4,4'-Bipyridine; Wiley: New York, NY, 1998.

40. Matsue, T.; Evans, D. H.; Osa, T.; Kobayashi, N. J. Am. Chem. Soc. 1985, 107, 3411-3417.

41. Isnin, R.; Salam, C.; Kaifer, A. E. J. Org. Chem. 1991, 56, 35-41.

42. Mirzoian, A.; Kaifer, A. E. Chem.-Eur. J. 1997, 3, 1052-1058.

43. Wang, Y.; Mendoza, S.; Kaifer, A. E. Inorg. Chem. 1998, 37, 317-320.

44. Gutsche, C. D.; Iqbal, M.; Stewart, D. J. Org. Chem. 1986, 51, 742-745.

45. Atwood, J. L.; Orr, G. W.; Means, N. C.; Hamada, F.; Zhang, H.; Bott, S. G.; Robinson, K. D. Inorg. Chem. 1992, 31, 603-606.

46. Suga, K.; Ohzono, T.; Negishi, M.; Deuchi, K.; Morita, Y. Supramol. Sci. 1998, 5, 9-14.

47. Yoshida, I.; Yamamoto, N.; Sagara, F.; Ishii, D.; Ueno, K.; Shinkai, S. Bull. Chem. Soc. Jpn. 1992, 65, 1012-1015.

48. Group, S. E. Instrumental Methods in Electrochemistry; Eilis Horwood: Southampton, 1985.

49. Walcarius, A.; Lamberts, L. J. Electroanal. Chem. 1996, 406, 59-68. 